\title{
Stretch your heart-but not too far: The role of titin mutations in dilated cardiomyopathy
}

Eric J. Stöhr, PhD, ${ }^{\mathrm{a}, \mathrm{b}}$ Hiroo Takayama, $\mathrm{MD}, \mathrm{PhD},{ }^{\mathrm{c}}$ and Giovanni Ferrari, $\mathrm{PhD}^{\mathrm{c}}$

\footnotetext{
From the ${ }^{\mathrm{a} D i v i s i o n}$ of Cardiology, Department of Medicine, and ${ }^{\mathrm{c} D i v i s i o n}$ of Cardiothoracic and Vascular Surgery, Department of Surgery, Columbia University Irving Medical Center, New York, NY; and ${ }^{b}$ School of Health Sciences, Cardiff Metropolitan University, Cardiff, United Kingdom.

G.F. is supported by the National Institutes of Health R01-HL131872 and HL122805, American Heart Association Grant 24810002, The Kibel Fund for Aortic Valve Research, and The Valley Hospital Foundation "Marjorie C Bunnel" charitable fund. E.J.S. is supported by a grant from the European Union's Horizon 2020 research and innovation program under the Marie Skłodowksa-Curie Grant Agreement Number 705219.

Received for publication July 26, 2017; revisions received Sept 29, 2017; accepted for publication Oct 24, 2017; available ahead of print April 20, 2018

Address for reprints: Eric J. Stöhr, PhD, Division of Cardiology, Department of Medicine, Columbia University Irving Medical Center, 630 West 168th St, P\&S Building, 10-508B, New York, NY 10-508B (E-mail: ejs2212@cumc.columbia.edu).

J Thorac Cardiovasc Surg 2018;156:209-14

$0022-5223 / \$ 36.00$

Copyright (c) 2018 by The American Association for Thoracic Surgery

https://doi.org/10.1016/j.jtcvs.2017.10.160
}

Cardiomyopathies are a heterogeneous group of diseases that negatively affect heart structure and function. An enlarged and weakened left ventricle (LV) characterizes dilated cardiomyopathy (DCM). Clinical studies have reported that approximately $50 \%$ of patients with DCM have a first-degree relative affected or likely to be affected, implicating a genetic cause. However, mutations have been found only in a small subgroup of patients. Titin, encoded by the TTN gene, is a sarcomeric protein present in skeletal muscle, smooth muscle, and cardiac muscle and is highly involved in the mechanotransduction and stretch of the heart muscle. ${ }^{1,2}$ The advantages and disadvantages of cardiac adaptation to stress and stretch have been the subject of several studies highlighting the role of titin in development and disease, summarized in recent review articles. ${ }^{3-5}$ With its discovery often dated back to 1976 when it was still called "connectin," 6 titin has been highlighted in cardiac physiology/medicine because of its possible contribution to the Frank-Starling mechanism and its implication in DCM. ${ }^{5,7-10}$

Initially, titin's structural properties related it mostly to sarcomeric integrity and passive stiffness, which was shown to be altered in cardiac disease. ${ }^{11,12}$ More recently, our knowledge has been extended beyond passive stiffness to active (and passive) muscle force production ${ }^{13,14}$ and the impact of titin mutations in the development of cardiac disease $^{15,16}$ as highlighted in the report by Hinson and colleagues. ${ }^{17}$ In this article, we provide a brief review of the different titin isoforms and their associated elasticity, and discuss recent links with cardiac disease.

\section{WHAT IS TITIN?}

With a molecular weight of 3.0 to $3.8 \mathrm{MDa},{ }^{18}$ titin is also often called the "giant protein." ${ }^{, 19,20}$ Titin spans approximately half of the sarcomeres in cardiac and skeletal

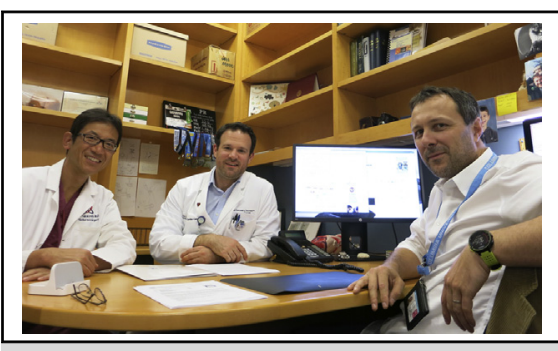

Hiroo Takayama, MD, PhD (left), Eric J. Stöhr, PhD (middle), and Giovanni Ferrari, PhD (right).

\section{Central Message}

Titin $(T T N)$ is an elastic molecule located within the sarcomeres of muscle. TTN contributes to the Frank-Starling mechanism, and genetic mutations have been linked to DCM.

See Editorial Commentary page 215.

muscles, and is located between the Z-disk and M-band within the sarcomere (Figure 1). The total structure is divided into different segments at specific locations. The presence, absence, or relative contribution of segments represents different isoforms that act like springs with different magnitudes of stiffness (Figure 2). ${ }^{8,21}$ Although titin has also been shown to be modifiable by phosphorylation and oxidation, an isoform switch has been described and linked to normal developmental stages as well as disease. Currently, 3 cardiac isoforms of different lengths and stiffnesses/ elasticities have been described. The longest and most elastic isoform can be found in neonates. ${ }^{20}$ The mediumlength isoform is found in healthy adult myocardium, whereas the shortest, most stiff isoform has been reported in the myocardium of adults with heart failure (Figure 3). ${ }^{10,22}$

\section{TITIN AND THE FRANK-STARLING MECHANISM}

The Frank-Starling mechanism relates to a change in the end-diastolic stretch of the LV and represents on the myocyte level as sarcomere stretch, resulting in a subsequently greater force of contraction and a greater stroke volume. ${ }^{23}$ Historically, the stretch-induced increased contractility of the heart has been linked to a change in the myofilament $\mathrm{Ca}^{2+}$ sensitivity. It has been proposed that sarcomere stretch is transmitted to sensitivity of myocardial calcium ions, which has been termed "length-dependent activation." However, some debate remains around the exact mechanism and recent evidence suggests that titin may contribute significantly to length-dependent activation through 


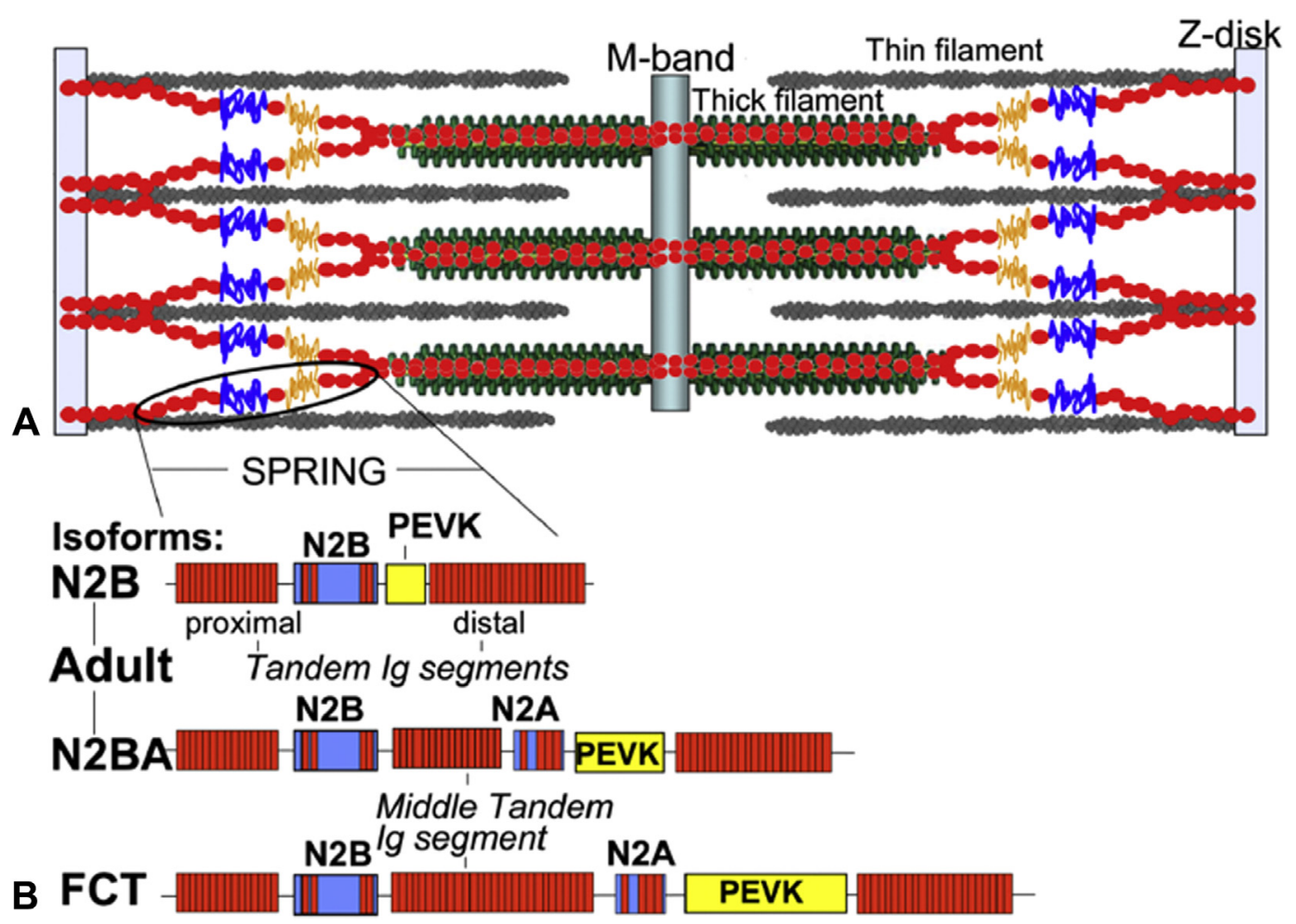

FIGURE 1. Domain structure of titin-isoforms within the sarcomere. A, The spring segment. B, Difference in the domain structure of different isoforms. PEVK, Proline $(\mathrm{P})$, glutamate $(\mathrm{E})$, valine $(\mathrm{V})$, and lysine $(\mathrm{K}) ; P K C$, protein kinase $\mathrm{C} ; P K A$, protein kinase A; $P K G$, cyclic guanosine monophosphate (cGMP)-dependent protein kinase; $F C T$, fetal cardiac titin. Figure and text reproduced from Gigli and colleagues, ${ }^{5}$ under the Creative Commons Attribution License (CC-BY).

structural rearrangements of both thin- and thick-filament proteins. ${ }^{24}$ This indicates that titin is involved in passive stretch-sensing that simultaneously acts on thin and thick filaments. Although these advances in our knowledge highlight the potential of titin to impact on the most fundamental whole-organ function of the heart, another discovery increases the significance of titin even more. In addition to contributing to length-dependent activation, titin appears to contribute to the Frank-Starling mechanism by linking the transition from end-systole to the early diastolic period. Helmes and colleagues ${ }^{25}$ showed that titin's restoring forces are involved when the sarcomere shortens below slack length (ie, a reduced end-systolic volume on the wholeorgan level), and the subsequent early diastolic recoil may be influenced by length-dependent deactivation. These findings emphasize the importance of titin's molecular contributions to the whole-organ regulation of cardiac function during contraction and relaxation. Moreover, the link between systole and diastole fits the previously observed involvement of titin in DCM. From a classic FrankStarling perspective and the data discussed at the beginning of this paragraph, titin could be expected to upregulate myofilament $\mathrm{Ca}^{2+}$ sensitivity and increase the force of contraction. The lack of such a response in DCM can now be explained, at least in part, by the inability of the heart to shorten below slack-length, and consequently the heart finds itself in a negative spiral that results in increased stiffness, affecting both systole and diastole. Elucidating the exact interaction between titin stiffness and systole/ diastole is essential to understand heart function on a more fundamental level. This was elegantly highlighted by a recent article that suggested an improved diastolic function with increased titin compliance, but with the additional effect of an attenuated Frank-Starling mechanism. ${ }^{26}$ Future studies should focus more on the role of titin from the early stages of heart failure and the transition to DCM to understand the interplay between systolic and diastolic regulation.

\section{TITIN'S REGULATORY CAPACITY}

The truly remarkable thing about titin is its ability to modify in relation to its tension, thereby appearing to be able to regulate across a wide range of stiffnesses/elasticities. For example, titin has been shown to be altered by S-glutathionylation, ${ }^{27}$ as well as by phosphorylation and oxidation. ${ }^{28,29}$ These modifications may play important roles in the acute and chronic regulation of cardiac function and could be therapeutic targets. The pathologically altered titin phosphorylation in heart failure, possibly not dissimilar to the consequences of 

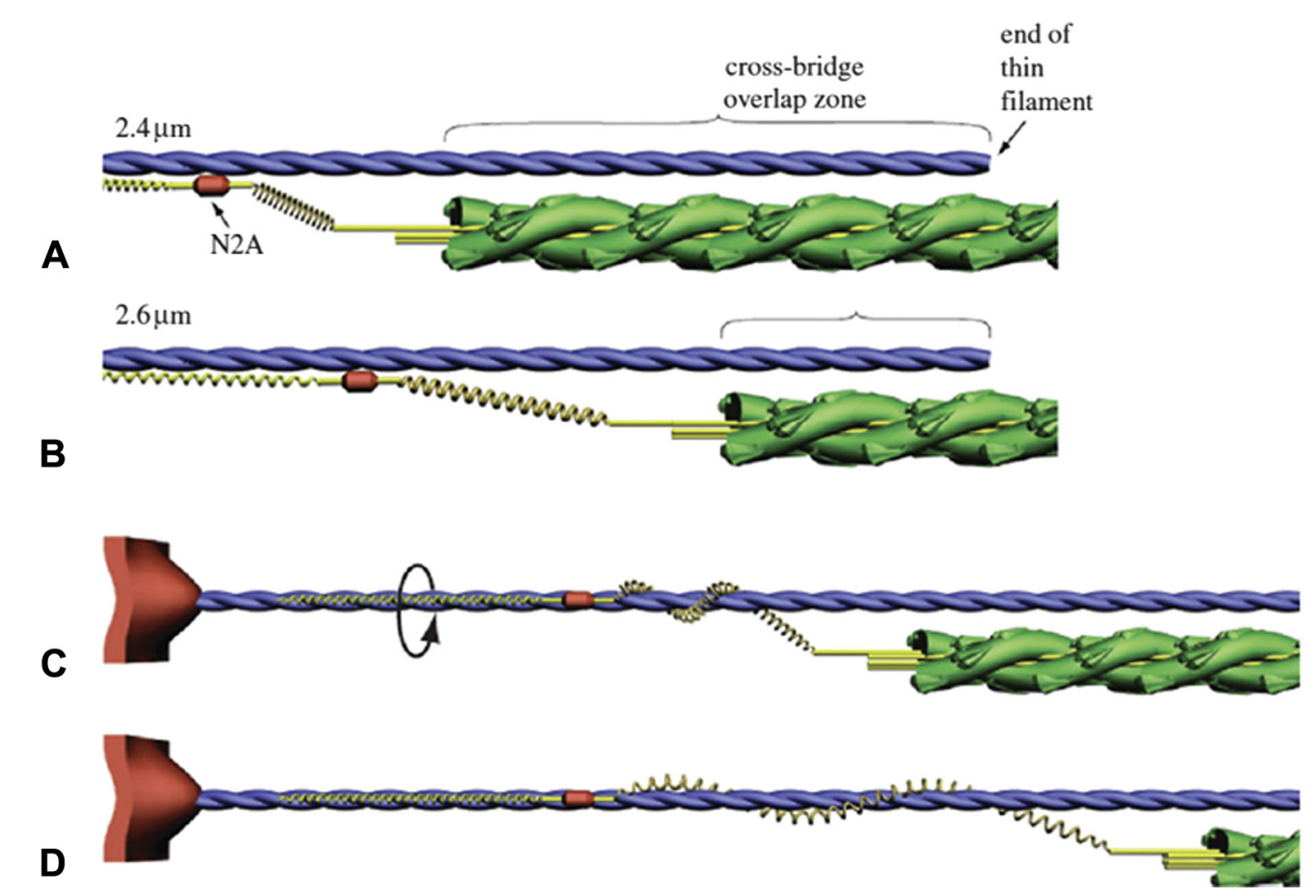

FIGURE 2. Schematic representation of titin's spring-like function and the winding filament hypothesis. ${ }^{21} \mathrm{~A}$ and $\mathrm{B}, \mathrm{Ca} 2^{+}$-dependent binding of N2A to thin filaments contributes to length-tension relationship [Frank-Starling]. If $\mathrm{N} 2 \mathrm{~A}$ (red) binds nonselectively to thin filaments (blue) in the presence of Ca2 ${ }^{+}$, and if the binding site depends on sarcomere length at the time of $\mathrm{Ca}_{2}{ }^{+}$influx, then a plateau is predicted in active force at sarcomere lengths between (A) 2.4 and (B) $2.6 \mathrm{~mm}$ in rabbit psoas muscle. C and D, Cross-bridge cycling results in titin winding. C, Cycling of the cross-bridges winds PEVK on the thin filaments (arrow indicates direction of rotation). In the model, the winding angle depends only on sarcomere geometry. D, Stretch of an active sarcomere extends the PEVK segment and enhances the active force. Figure reproduced with permission and adapted from Nishikawa and colleagues. ${ }^{21}$

titin mutations mentioned previously, ${ }^{15-17}$ is a current area of interest that has raised the hope that isoform splicing and post-translational modification of titin's I-band region ${ }^{30}$ could alleviate the cardiac stiffness observed in a number of pathologies. Elegant studies have shown that

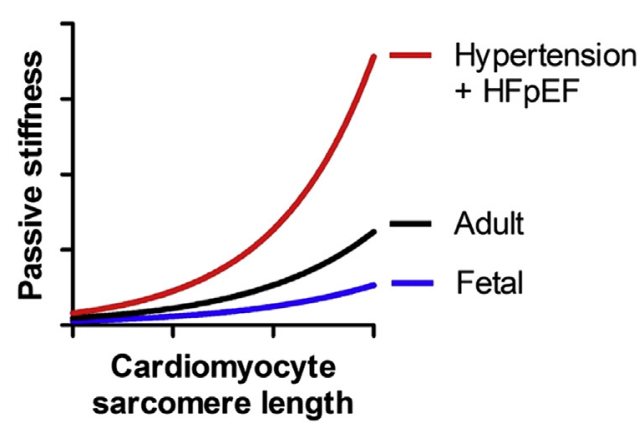

FIGURE 3. Different passive stiffness of cardiac muscle in populations with different titin isoforms. Passive stiffness of the normal adult titin isoform N2BA is shown across a range of sarcomere lengths. In fetal myocardium, the more elastic titin isoform (fetal cardiac titin [FCT]) is associated with a reduced passive stiffness. Conversely, in patients with hypertension and heart failure with preserved ejection fraction, the shorter N2B isoform is characterized by increased myocardial stiffness. $H F p E F$, Heart failure with preserved ejection fraction. Schematic based on Lahmers and colleagues $^{21}$ and Zile and colleagues. ${ }^{11}$ phosphorylation of protein kinases $\mathrm{A}, \mathrm{G}$, and $\mathrm{C}$ can alter titin-based passive stiffness by phosphorylating titin at the N2B element or the PEVK sequence. ${ }^{30}$ These modifications have been examined in a number of animal models of disease, as well as in humans, including in healthy hearts obtained from organ donors, ${ }^{31}$ patients with $\mathrm{DCM},{ }^{32}$ and patients with heart failure and preserved ejection fraction who were also hypertensive. ${ }^{11}$ There is no doubt that the recent findings hold a significant promise in alleviating the problems associated with a variety of heart failure types. However, caution must be exercised, because TTN manipulations via post-translational phosphorylation may be accompanied by unexpected (and unwanted) additional modifications as suggested in other genetic studies. ${ }^{33}$ This is in agreement with the fundamental physiologic principle of redundancy, emphasizing the need for careful checking of the consequences of molecular alterations to wholeorgan function. ${ }^{34}$ Notwithstanding, the ability of titin to modify its passive stiffness/elasticity in response to phosphorylation deserves further investigation.

\section{THE MISSING LINK}

The aforementioned evidence mostly originates from elegant studies of isolated myofibers or even single 
molecules. However, the link to whole-organ function is less clear. In the healthy human LV, oblique and circumferential myofibers interact during contraction to result in twist (sometimes termed "torsion"), and rapid untwisting occurs during relaxation. ${ }^{35}$ In particular, the rapid untwisting, which is in part a passive process related to restoring forces and in part elastic recoil, is conceptually linked to LV stiffness. ${ }^{36}$ But despite previous reference to the link between LV twist/untwisting and titin, ${ }^{37,38}$ to the best knowledge of the authors direct empirical evidence between titin isoforms and LV twist/untwisting is missing. One previous study has highlighted the influence of altered ventricular myosin-light-chain-2 on LV twist ("torsion"), ${ }^{39}$ but the link between the systolic and diastolic mechanical function and titin expression remains outstanding. Furthermore, the clinical relevance remains to be elucidated. To fully understand the interaction between the mechanical behavior on the myocyte level and the overall wholeorgan function is essential if conditions such as DCM are to be treated successfully, maybe even prevented. Largescale evidence for this is missing; however, there is interest in the field of mechanobiology and biomatrices in general and the example of titin, torsion, and DCM is a perfect example for the need for such endeavors. ${ }^{40,41}$ This may extend to a better understanding of the interaction between elasticity of the sarcomeric titin, whole-organ stress/tension (as perhaps represented by LV twist/torsion), ${ }^{42,43}$ and surgically implanted cardiac assist devices. We recommend that future studies could significantly expand our existing knowledge by providing molecular evidence obtained from tissue samples during surgical interventions and coupling them with noninvasive indices of whole-organ cardiac mechanics.

\section{DILATED CARDIOMYOPATHY AND THE \\ GENETICS OF TTN}

A large body of evidence suggests a familiar aggregation of DCM. As described in recent work, the autosomaldominant inheritance is the predominant pattern of transmission; however, some familial cases also present an autosomal recessive or X-linked recessive trait. Recent studies classify pathogenic variants in the TTN gene as the main responsible for familial DCM with approximately $30 \%$ to $35 \%$ of families diagnosed of DCM showing any alteration in this gene. The second gene most prevalent in familial DCM is LMNA, responsible for approximately $10 \%$ to $15 \%$ of cases. Haas and colleagues ${ }^{44}$ report in detail the variants of TTN in DCM and weight their effect on the basis of gene size, number of splice, frameshift, stop, nonsynonymous, and predicted disease-causing nonsynonymous variants. TTN truncating mutations have been reported to be the common cause of DCM, occurring in approximately $25 \%$ of familial cases of idiopathic DCM and in $18 \%$ of sporadic case. ${ }^{45}$ Notably, the clinical manifestations in titin mutations are similar, related to symptoms, morbidity, and mortality, but the disease is more aggressive with adverse events in men at earlier ages. $^{16,45}$

With regard to post-translational modifications, as mentioned earlier, phosphorylation of protein kinases $\mathrm{A}, \mathrm{G}$, and $\mathrm{C}$ can alter titin-based passive stiffness by phosphorylating titin at the N2B element or the PEVK sequence. ${ }^{30}$ From a clinical perspective, it remains important to determine the contribution of titin-based stiffness to overall stiffness reported in heart failure. ${ }^{46}$ Collagen fragmentation or deposition may also contribute to total cardiac stiffness, ${ }^{10,11}$ and in an experimental model of DCM other extracellular matrix proteins appeared to play a more important role in overall stiffness compared with titin contributions. ${ }^{47}$ Extending this suggestion on titin-related contributions to both the systolic and diastolic whole-organ cardiac function, future studies should attempt to determine which structural and nonstructural proteins from the extracellular matrix may contribute to cardiac stiffness, either directly through tissue stiffness or indirectly via mechanotranduction. ${ }^{48}$

\section{SURGEONS' CORRECTION OF DILATED}

\section{CARDIOMYOPATHY, THE COLLECTION OF} TITIN, AND CONNECTION WITH BASIC SCIENCE

Although the genetic understanding of DCM is rapidly advancing (TTN is being considered as one of the most responsive among $>50$ identified gene mutations) and genetic testing has been implemented in patient management as an important tool in screening and diagnosis, its therapeutic implication is still limited. Pathologic mechanisms of DCM are knowingly diverse, involving alterations in metabolic profiles, nuclear integrity, transcriptional regulation, protein degradation, and calcium ion channel, ${ }^{49}$ highlighting its genetic complexity. Pharmacologic and implantable cardioverter-defibrillator therapies remain the mainstream in the management of patients with DCM until they progress to Stage D heart failure, in which surgical interventions, such as heart transplantation and mechanical circulatory assist devices, contribute significantly as a standard of care of these patients. Assessment of titin-based stiffness may be used in the future to further determine the necessity of surgery, as well as to determine the outcome of surgical interventions. Of note, surgical correction of aortic stenosis may also result in alterations in titin, with consequences that are yet to be fully determined. ${ }^{50}$ In essence, titin's role in relation to passive cardiac tension means that theoretically any surgery that results in a change in shape, volume, or pressure of the heart with subsequent alterations in wall tension is likely to influence titin. $^{42,51-53}$ Whether there is a direct link between surgical interventions that have successfully restored LV twist/torsion ${ }^{54,55}$ and titin remains to be confirmed in future research studies. Indirect effects through 
thymectomies have been reported ${ }^{56}$ highlighting the wider implications of any structural and endocrine modification to potentially affect titin. Moreover, in the (near) future, the development of a genetic therapy for Stage D heart failure, surgical interventions might play an important role similar to studies in regeneration therapy in which various cells or matrices are injected into myocardium at the time of durable left ventricular assist device implantation.

\section{CONCLUSIONS}

To improve our knowledge of the role of titin on DCM, a more complex multidisciplinary approach is required. A systematic ex vivo analysis of explanted tissue for genomic, transcriptomic, proteomic analysis would generate important insights into the role of TTN in DCM and possibly allow a novel risk-stratification tool for patients in need of medical device implantation. Furthermore, given the correlation between titin and troponin/tropomysin in the FrankStarling mechanism, an ex vivo mechanobiological analysis of surgical explants would also inform the patient response to changes in stress and strain. Overall, titin represents a key player in DCM, and a more interdisciplinary analysis of its regulation and impact of cardiac remodeling may assist in improving the understanding and treatment of DCM.

\section{Conflict of Interest Statement}

Authors have nothing to disclose with regard to commercial support.

\section{References}

1. Leppanen M, Aaltonen S, Parkkari J, Heinonen A, Kujala UM. Interventions to prevent sports related injuries: a systematic review and meta-analysis of randomised controlled trials. Sports Med. 2014;44:473-86.

2. Kruse NT, Scheuermann BW. Cardiovascular responses to skeletal muscle stretching: "Stretching" the truth or a new exercise paradigm for cardiovascular medicine? Sports Med. 2017;47:2507-20.

3. Sequeira V, van der Velden J. The Frank-Starling Law: a jigsaw of titin proportions. Biophys Rev. 2017;9:259-67.

4. Gigli M, Begay RL, Morea G, Graw SL, Sinagra G, Taylor MR, et al. A review of the giant protein titin in clinical molecular diagnostics of cardiomyopathies. Front Cardiovasc Med. 2016;3:21.

5. Hamdani N, Herwig M, Linke WA. Tampering with springs: phosphorylation of titin affecting the mechanical function of cardiomyocytes. Biophys Rev. 2017;9: 225-37.

6. Maruyama K. Connectin, an elastic protein from myofibrils. J Biochem. 1976;80: 405-7.

7. Granzier HL, Labeit S. The giant protein titin: a major player in myocardial mechanics, signaling, and disease. Circ Res. 2004;94:284-95.

8. LeWinter MM, Granzier H. Cardiac titin: a multifunctional giant. Circulation. 2010;121:2137-45.

9. Dos Remedios C, Gilmour D. An historical perspective of the discovery of titin filaments. Biophys Rev. 2017;9:179-88.

10. Hamdani N, Paulus WJ. Myocardial titin and collagen in cardiac diastolic dysfunction: partners in crime. Circulation. 2013;128:5-8.

11. Zile MR, Baicu CF, Ikonomidis J, Stroud RE, Nietert PJ, Bradshaw AD, et al. Myocardial stiffness in patients with heart failure and a preserved ejection fraction: contributions of collagen and titin. Circulation. 2015;131:1247-59.

12. Hidalgo $\mathrm{C}$, Granzier $\mathrm{H}$. Tuning the molecular giant titin through phosphorylation: role in health and disease. Trends Cardiovasc Med. 2013;23:165-71.
13. Rivas-Pardo JA, Eckels EC, Popa I, Kosuri P, Linke WA, Fernandez JM. Work done by titin protein folding assists muscle contraction. Cell Rep. 2016;14 $1339-47$.

14. Martonfalvi Z, Bianco P, Naftz K, Ferenczy GG, Kellermayer M. Force generation by titin folding. Protein Sci. 2017;26:1380-90.

15. Gerull B, Gramlich M, Atherton J, McNabb M, Trombitas K, Sasse-Klaassen S, et al. Mutations of TTN, encoding the giant muscle filament titin, cause familial dilated cardiomyopathy. Nat Genet. 2002;30:201-4.

16. Herman DS, Lam L, Taylor MR, Wang L, Teekakirikul P, Christodoulou D, et al Truncations of titin causing dilated cardiomyopathy. N Engl J Med. 2012;366: 619-28.

17. Hinson JT, Chopra A, Nafissi N, Polacheck WJ, Benson CC, Swist S, et al HEART DISEASE. Titin mutations in iPS cells define sarcomere insufficiency as a cause of dilated cardiomyopathy. Science. 2015;349:982-6.

18. Labeit S, Lahmers S, Burkart C, Fong C, McNabb M, Witt S, et al. Expression of distinct classes of titin isoforms in striated and smooth muscles by alternative splicing, and their conserved interaction with filamins. J Mol Biol. 2006;362: 664-81.

19. Bang ML, Centner T, Fornoff F, Geach AJ, Gotthardt M, McNabb M, et al. The complete gene sequence of titin, expression of an unusual approximately 700$\mathrm{kDa}$ titin isoform, and its interaction with obscurin identify a novel Z-line to Iband linking system. Circ Res. 2001;89:1065-72.

20. Lahmers S, Wu Y, Call DR, Labeit S, Granzier H. Developmental control of titin isoform expression and passive stiffness in fetal and neonatal myocardium. Circ Res. 2004;94:505-13.

21. Nishikawa KC, Monroy JA, Uyeno TE, Yeo SH, Pai DK, Lindstedt SL. Is titin a 'winding filament'? A new twist on muscle contraction. Proc Biol Sci. 2012;279: 981-90.

22. Zile MR, Baicu CF, Ikonomidis JS, Stroud RE, Nietert PJ, Bradshaw AD et al. Myocardial stiffness in patients with heart failure and a preserved ejection fraction: contributions of collagen and titin. Circulation. 2015;131: 1247-59.

23. Patterson SW, Piper H, Starling EH. The regulation of the heart beat. J Physiol. 1914;48:465-513.

24. Ait-Mou Y, Hsu K, Farman GP, Kumar M, Greaser ML, Irving TC, et al. Titin strain contributes to the Frank-Starling law of the heart by structural rearrangements of both thin- and thick-filament proteins. Proc Natl Acad Sci U S A 2016;113:2306-11.

25. Helmes M, Lim CC, Liao R, Bharti A, Cui L, Sawyer DB. Titin determines the Frank-Starling relation in early diastole. J Gen Physiol. 2003;121:97-110.

26. Methawasin M, Hutchinson KR, Lee EJ, Smith JE III, Saripalli C, Hidalgo CG et al. Experimentally increasing titin compliance in a novel mouse model attenuates the Frank-Starling mechanism but has a beneficial effect on diastole. Circulation. 2014;129:1924-36.

27. Alegre-Cebollada J, Kosuri P, Giganti D, Eckels E, Rivas-Pardo JA, Hamdani N et al. S-glutathionylation of cryptic cysteines enhances titin elasticity by blocking protein folding. Cell. 2014;156:1235-46.

28. Hamdani N, Franssen C, Lourenco A, Falcao-Pires I, Fontoura D, Leite S, et al Myocardial titin hypophosphorylation importantly contributes to heart failure with preserved ejection fraction in a rat metabolic risk model. Circ Heart Fail. 2013;6:1239-49.

29. Hamdani N, Herwig M, Linke WA. Tampering with springs: phosphorylation of titin affecting the mechanical function of cardiomyocytes. Biophys Rev. 2017;9 225-37.

30. Anderson BR, Granzier HL. Titin-based tension in the cardiac sarcomere: molecular origin and physiological adaptations. Prog Biophys Mol Biol. 2012;110: 204-17.

31. Kruger M, Linke WA. Protein kinase-A phosphorylates titin in human heart muscle and reduces myofibrillar passive tension. J Muscle Res Cell Motil. 2006;27: 435-44.

32. Kruger M, Kotter S, Grutzner A, Lang P, Andresen C, Redfield MM, et al. Protein kinase $\mathrm{G}$ modulates human myocardial passive stiffness by phosphorylation of the titin springs. Circ Res. 2009;104:87-94.

33. Schaefer KA, Wu WH, Colgan DF, Tsang SH, Bassuk AG, Mahajan VB. Unexpected mutations after CRISPR-Cas9 editing in vivo. Nat Methods. 2017;14: 547-8.

34. Joyner MJ. Physiology and redundancy. Physiology (Bethesda). 2013;28:136-7.

35. Stöhr EJ, Shave RE, Baggish AL, Weiner RB. Left ventricular twist mechanics in the context of normal physiology and cardiovascular disease: a review of studies using speckle tracking echocardiography. Am J Physiol Heart Circ Physiol. 2016:311:H633-44. 
36. Opdahl A, Remme EW, Helle-Valle T, Edvardsen T, Smiseth OA. Myocardial relaxation, restoring forces, and early-diastolic load are independent determinants of left ventricular untwisting rate. Circulation. 2012;126:1441-51.

37. Pasipoularides A. LV twisting and untwisting in HCM: ejection begets filling. Diastolic functional aspects of HCM. Am Heart J. 2011;162:798-810.

38. Notomi Y, Martin-Miklovic MG, Oryszak SJ, Shiota T, Deserranno D, Popovic ZB, et al. Enhanced ventricular untwisting during exercise: a mechanistic manifestation of elastic recoil described by Doppler tissue imaging. Circulation. 2006;113:2524-33.

39. Sheikh F, Ouyang K, Campbell SG, Lyon RC, Chuang J, Fitzsimons D, et al Mouse and computational models link Mlc2v dephosphorylation to altered myosin kinetics in early cardiac disease. J Clin Invest. 2012;122:1209-21.

40. Guo CL, Harris NC, Wijeratne SS, Frey EW, Kiang CH. Multiscale mechanobiology: mechanics at the molecular, cellular, and tissue levels. Cell Biosci. 2013;3: 25.

41. Mak M, Kim T, Zaman MH, Kamm RD. Multiscale mechanobiology: computational models for integrating molecules to multicellular systems. Integr Biol (Camb). 2015;7:1093-108.

42. Carruth ED, McCulloch AD, Omens JH. Transmural gradients of myocardial structure and mechanics: implications for fiber stress and strain in pressure overload. Prog Biophys Mol Biol. 2016;122:215-26.

43. van Mil ACCM, Drane A, Pearson J, McDonnell B, Cockcroft JR, Stöhr EJ. Interaction of LV twist with arterial haemodynamics during localised, non-metabolic hyperaemia with and without blood flow restriction. Exp Physiol. 2016;101: 509-20.

44. Haas J, Frese KS, Peil B, Kloos W, Keller A, Nietsch R, et al. Atlas of the clinical genetics of human dilated cardiomyopathy. Eur Heart J. 2015;36:1123-35. a.

45. Perez-Serra A, Toro R, Sarquella-Brugada G, de Gonzalo-Calvo D, Cesar S, Carro E, et al. Genetic basis of dilated cardiomyopathy. Int J Cardiol. 2016; 224:461-72.
46. Zile MR, Baicu CF, Gaasch WH. Diastolic heart failure-abnormalities in active relaxation and passive stiffness of the left ventricle. $N$ Engl J Med. 2004;350: 1953-9.

47. Jaber WA, Maniu C, Krysiak J, Shapiro BP, Meyer DM, Linke WA, et al. Titin isoforms, extracellular matrix, and global chamber remodeling in experimental dilated cardiomyopathy: functional implications and mechanistic insight. Circ Heart Fail. 2008;1:192-9.

48. Rienks M, Papageorgiou AP, Frangogiannis NG, Heymans S. Myocardial extracellular matrix: an ever-changing and diverse entity. Circ Res. 2014;114:872-88.

49. Weintraub RG, Semsarian C, Macdonald P. Dilated cardiomyopathy. Lancet. 2017;390:400-14.

50. Williams L, Howell N, Pagano D, Andreka P, Vertesaljai M, Pecor T, et al. Titin isoform expression in aortic stenosis. Clin Sci (Lond). 2009;117:237-42.

51. Choi HF, D’Hooge J, Rademakers FE, Claus P. Influence of left-ventricular shape on passive filling properties and end-diastolic fiber stress and strain. $J$ Biomech. 2010;43:1745-53.

52. van Dalen BM, Kauer F, Vletter WB, Soliman OI, van der Zwaan HB, Ten Cate FJ, et al. Influence of cardiac shape on left ventricular twist. J Appl Physiol (1985). 2010;108:146-51.

53. Cirillo M, Villa E, Campana M, Troise G. Renewal of left ventricular torsion after modified surgical anterior ventricular restoration. J Cardiovasc Med (Hagerstown). 2008;9:1142-6.

54. Cirillo M. A new surgical ventricular restoration technique to reset residual myocardium's fiber orientation: the "KISS" procedure. Ann Surg Innov Res. 2009;3:6.

55. Cirillo M, Campana M, Brunelli F, Dalla Tomba M, Mhagna Z, Messina A, et al. Time series analysis of physiologic left ventricular reconstruction in ischemic cardiomyopathy. J Thorac Cardiovasc Surg. 2016;152:382-91.

56. Chen XJ, Qiao J, Xiao BG, Lu CZ. The significance of titin antibodies in myasthenia gravis-correlation with thymoma and severity of myasthenia gravis. J Neurol. 2004;251:1006-11. 